\title{
periferio
}

\section{A DEFICIÊNCIA E AS POLIITICAS SOCIAIS EM PORTUGAL: RETRATO DE UMA DEMOCRACIA EM CURSO}

\author{
Bruno Sena Martins 1 \\ Universidade de Coimbra
}

\section{Resumo}

A realidade pessoas com deficiência em Portugal é marcada por fortíssimas condições de marginalização social e exclusão económica. Um tal quadro emerge a despeito das sucessivas transformações legislativas e das políticas sociais que foram sendo introduzidas nas últimas décadas. A superação deste contexto passa por um radical questionamento dos termos pelos quais a deficiência é pensada, tanto quanto por uma transformação de dinâmicas democráticas acostumadas a negligenciar as vozes das pessoas com deficiência.

Palavras-chave: deficiência; corpo; políticas sociais

\footnotetext{
${ }^{1}$ Investigador do Centro de Estudos Sociais da Universidade de Coimbra (CES). Vice-presidente Conselho Científico e de Co-coordenador no Programa de extensão académica "O Ces vai à Escola." Co-coordenador do Programa de Doutoramento "Human Rights in Contemporary Societies." Docente no Programa de Doutoramento "Pós-colonialismos e cidadania global." Licenciado em antropologia e doutorado em sociologia. bsenamartins@gmail.com
} 


\section{periferio}

DISABILITY AND SOCIAL POLICIES IN PORTUGAL: A PORTRAIT OF AN ONGOING DEMOCRACY

\section{Abstract}

The social reality of Disabled People in Portugal is characterized by blatant conditions of social marginalization and economic exclusion. Such a scenario is drawn despite continuous legislative transformations and social policies consistently introduced in recent decades. The overcoming of this context depends both of a radical contestation of representing disability and of the democratic dynamics that neglect the voices the voices of disabled people.

Keywords: disability; body; social policies 


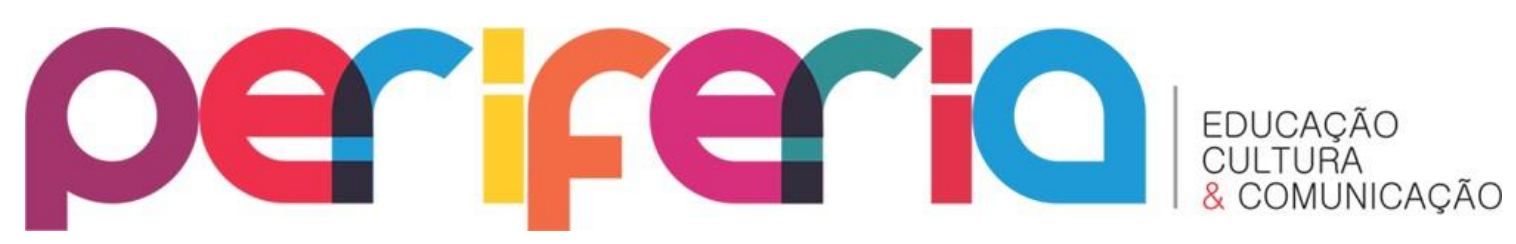

PREÂMBULO

"Percebe-se, tanto nas interações sociais como nas políticas sociais, o presente domínio de uma visão individual e trágica da deficiência" (OLIVER, 1990, p. 3)

As palavras de Michael Oliver, acima transcritas, refletem aquilo que entendo ser uma estrutura transversal de exclusão que marca, ainda hoje, a realidade da deficiência no nosso país. Michael Oliver é autor de um livro que veio a marcar fortemente as leituras da deficiência no mundo ocidental. Em The Politics of Disablement (1990) Michael Oliver teve o mérito de sintetizar a nova concepção de deficiência surgida da luta política nos anos 1970 no contexto britânico, um movimento social que advogou a emancipação sociopolítica das pessoas com deficiência. Esse clima de contestação muito deveu ao Independent Living Movement surgido nos Estados Unidos da América no final dos anos 1960. A síntese de Oliver consagrou aquilo que viria a ser conhecido como o Modelo Social da Deficiência, uma perspetiva contrahegemónica acerca da deficiência com forte potencial de reflexivo e político. Tal perspetiva persiste, no entanto, pleno século XXI, bem longe do nosso senso comum. Intuir as razões dessa ausência significa conferir atenção ao que subsiste inamovível, significa entender a força de uma cultura incapacitante da deficiência, significa entender as razões profundas da vacuidade das sucessivas mudanças e significa, ainda, explorar as possibilidades que se mantêm reféns de uma sociedade que, como poderíamos dizer em ironia, por qualquer acidente perdeu uso dos seus princípios.

\section{ESTADO SOCIAL E POLÍTICAS INCLUSIVAS}

Após algumas décadas em que, com o continuado crescimento das despesas sociais, a conciliação entre acumulação e distribuição parecia uma real possibilidade no seio do Estado Providência, assistimos ao início da sua crise, nos países da sua criação, a partir dos anos 70. Uma crise que veio a 


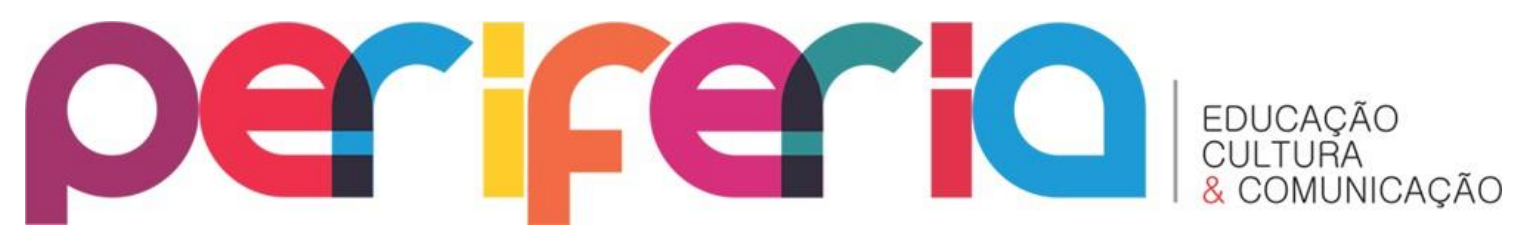

colocar em causa a ideia de que o crescimento do lucro se pode concertar com a permanência ou ampliação dos direitos sociais; nesse sentido verificase que "o capitalismo avançado que criou o Estado Providência se distancia progressivamente desta sua criação" (SANTOS, 1990, p. 205). A retração das políticas sociais aparece-nos assim como um fatalismo da economia capitalista, num processo que, como sabemos, muito tem devido à desregulação trazida pela intensificação da transnacionalização das trocas económicas sob a égide neoliberal.

Estas são as temporalidades e dinâmicas fundamentais que, com diferentes matizes, permitem ler a relação que as políticas sociais vêm mantendo com os horizontes de equidade e segurança social. No entanto, quando nos debruçamos sobre as condições de vida a que as pessoas com deficiência vêm sendo sujeitas, logo percebemos que as tendências gerais das políticas sociais só residualmente captam a sedimentada naturalização da sua exclusão social.

Primeiro, porque as pessoas com deficiência encontram-se entre os estratos populacionais mais empobrecidos e marginalizados das atividades centrais das nossas sociedades, algo que o desenvolvimentos das políticas sociais jamais vingou em confrontar de modo decisivo. Por isso, diluir a questão da deficiência no investimento público seria negligenciar o facto das políticas sociais nunca terem, alguma vez, vingado em forjado um trilho que elidisse significativamente a exclusão social da esmagadora maioria das pessoas com deficiência. Ou seja, há questões específicas e decisivas que nunca foram seriamente tomadas em conta para um redesenho social.

Em segundo lugar, mesmo na perspetiva de uma lógica economicista, pouco sentido pode fazer a omissão das pessoas com deficiência. A questão é simples: o investimento em "lógicas sociais paliativas", que mais não fazem do que assegurar a sobrevivência, mantendo as pessoas com deficiência nas franjas da sociedade, é bem mais oneroso do que uma requalificação social engendrada ao encontro da igualdade de oportunidades. Isso mesmo é referido no preâmbulo do American with Disabilities Act (ADA), a percursora 


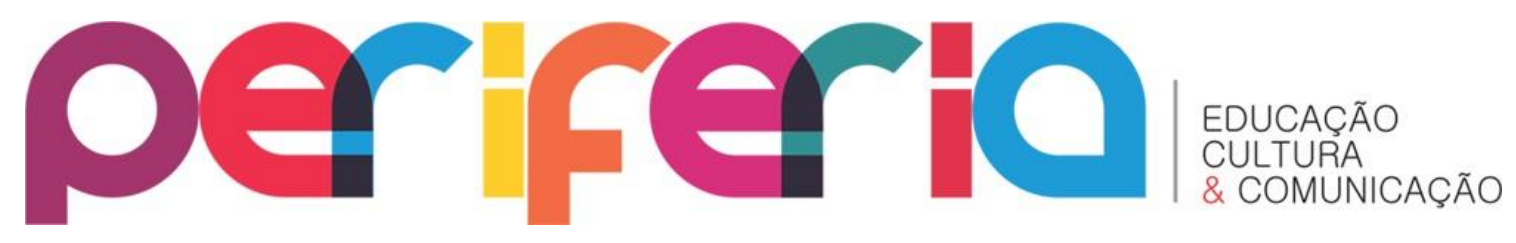

legislação americana antidiscriminatória, datada de 1990, quando refere os custos económicos da discriminação: "The continuing existence of unfair and unnecessary discrimination and prejudice denies people with disabilities the opportunity to compete on an equal basis and to pursue those opportunities for which our free society is justifiably famous, and costs the United States billions of dollars in unnecessary expenses resulting from dependency and nonproductivity".

Portanto, o que se torna instigante perceber é a estrutura de valores em que se sustenta a abordagem estreita que vem presidindo ao desenho e implementação de políticas que interessam (ou interessariam). É a este segundo aspeto que gostaria de me dedicar especialmente, numa leitura que ao questionar os paradigmas culturais e as práticas sociopolíticas que sustêm a concepção social dominante de deficiência, nos aproxima de Colin Barnes quando este autor, fazendo eco da realidade das pessoas com deficiência em diversos contextos do mundo ocidental, afirmava que "sem uma reestruturação radical da política social [...] existem poucas razões para um otimismo em relação ao futuro" (1999, p. 147).

\section{A OPRESSÃO DOS CORPOS}

Nas leituras críticas das sociedades contemporâneas é frequentemente denunciado o lugar que os corpos e as suas diferenças ocupam nos discursos legitimadores das relações de opressão, como locus de algumas das mais centrais formas de desigualdade e de controlo social na sociedade contemporânea (TURNER, 1994, p. 28). Por essa razão torna-se desafiante indagar: porque é que as situações de precariedade económica e exclusão social, amplamente enfrentadas pelas pessoas com deficiência - para falar das deficiências físicas - se encontram, quase sempre, tão invisibilizadas, tão longe das preocupações que marcam a agenda social? Algo que claramente contrasta, por exemplo, com a maior visibilidade adquirida pela denúncia das formas de subalternização baseadas na raça e na diferença sexual. Isto é tão 


\section{periferio}

mais instigante dada a significativa minoria populacional que as pessoas com deficiências constituem em todas as sociedades.

A questão é que a atribuição de limitações à atividade e à participação social ao corpo dito deficiente, tende a naturalizar poderosamente o vínculo à inferioridade e à experiência da exclusão social. Eis porque talvez se imponha - apelo a uma renovada sensibilidade analítica para que o fatalismo incapacitante que se assinala num corpo descrito como deficiente não permita uma insidiosa naturalização que nos impeça de perseguir os processos que saturam os corpos de valores e os demarcam. Portanto, a resposta para o sistemático adiamento dos trilhos de inclusão social (aqueles que a sociedade deverá percorrer, e não as pessoas com deficiência) reporta ao modo como o elemento biológico na base da opressão das pessoas com deficiência aparece mais resistente à desnaturalização da subalternidade do que aquele que está, por exemplo, na base das construções de raça ou diferença sexual. Isto assim é, primeiro, porque muitas deficiências poderão estar associadas, nalguns momentos, a formas de sofrimento e privação mais diretamente associadas com a experiência subjetiva do próprio corpo, aproximando-nos daquilo que noutro lugar (MARTINS, 2006) designei por "angústia da transgressão corporal". E, em segundo lugar, porque as deficiências nos colocam frequentemente perante formas de realização e interação diversas daquelas que nos habituámos a consagrar como normais à luz do fechamento de sentido promovido por uma perniciosa "hegemonia da normalidade" (DAVIS, 1995).

No entanto, nada disso nos deverá afastar da convicção de que o nãolugar que as pessoas com deficiência tendem a ocupar nas nossas sociedades se deve a persistência de uma estrutura excludente. Além dos valores e atitudes que as desqualificam, as pessoas com deficiência encontram barreiras arquitetónicas e comunicacionais, obstáculos no acesso aos transportes, ausência, insuficiência ou inadequação do apoio no sistema regular de educação, desigualdades no acesso à formação superior e ao emprego, etc. 


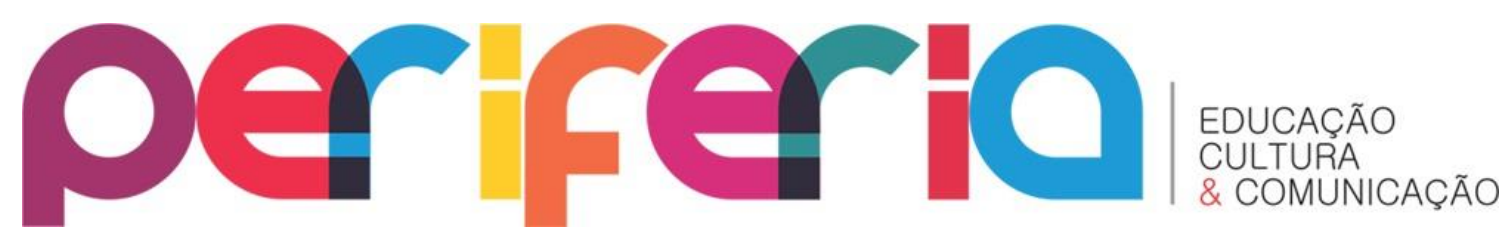

Estamos perante formas particularmente insidiosas de opressão social em que o elemento biológico individual da deficiência é tomado como justificação suficiente para a compreensão da sua não participação nas atividades centrais da sociedade. Refiro-me a representações onde as ideias de incapacidade, tragédia e infortúnio se congregam para apreender a existência das pessoas com deficiência à luz de uma "narrativa da tragédia pessoal” (OLIVER, 1990). Deste modo importa perceber porque é que um tal papel para as políticas sociais nunca se forjou, no sentido de conferir às pessoas com deficiência uma igualdade de oportunidades no acesso a arenas tão relevantes da vida social como a educação e o emprego. Tudo se passa como se um ciclo vicioso consentisse na invisibilidade do drama social ligado à esmagadora marginalização e pobreza das pessoas com deficiência. Um ciclo onde a invisibilidade das pessoas com deficiência consente na invisibilidade da opressão social que, finalmente, retira as pessoas com deficiência dos espaços sociais e económicos. È também neste ciclo que se ancora o domínio da abordagem reabilitacional como a abordagem privilegiada face à deficiência.

\section{A ABORDAGEM REABILITACIONAL}

No mundo ocidental as respostas sociais à deficiência estiveram marcadas durante muitos séculos pelas práticas da caridade cristã. Com a modernidade os Estados vieram crescentemente a chamar a si a definição de políticas para as pessoas com deficiência. Se dividirmos as políticas sociais por aqueles que foram os objetivos que presidiram à concepção do Estado Providência, temos, em primeiro lugar, a criação de serviços universais (como a saúde e a educação), em segundo, a criação de pleno emprego, e, em terceiro, a criação de uma rede de segurança social para agregados de baixos rendimentos e outros grupos vulneráveis (MISHRA, 1995). Partindo destes vetores é possível dizer que as políticas do Estado na modernidade começaram por abordar a deficiência pela terceira vertente, ou seja, através 


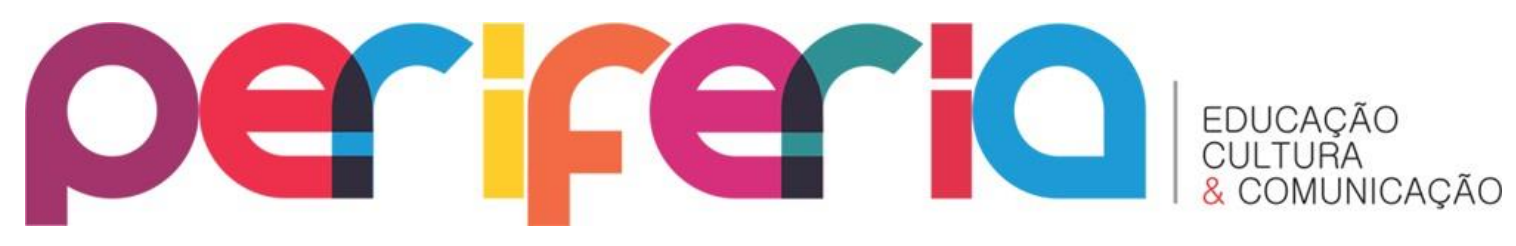

de uma assistência social capaz de dar algum amparo a um grupo particularmente vulnerável.

Nesse sentido, o assistencialismo da lógica caritária não sofreu grande mutação, havendo talvez apenas a destacar a proliferação de asilos especializados para as diferentes deficiências e o surgimento de instituições especializadas de ensino e formação profissional. Só no século XX os serviços dirigidos às pessoas com deficiência começaram a assumir alguma expressão fora de uma abordagem meramente assistencialista, dado para o qual foi decisivo o impacto dos soldados que ficaram deficientes nas Guerras Mundiais. Seriam eles a definir alguns dos avanços que acabariam por informar as respostas à restante população de pessoas com deficiência. Assim, com os países centrais do sistema mundial a assumirem uma posição de vanguarda, os discursos e práticas dirigidos às pessoas com deficiência começaram a enfatizar a necessidade destas serem socialmente reabilitadas e integradas. Criaram-se serviços de reabilitação, formação e inserção profissional, a opção pela educação nas instituições regulares de ensino começou-se a impor a partir da década de 60 e foi definida legislação para atender às necessidades específicas das pessoas com deficiência. No entanto, as políticas sociais ora se mostravam insuficientes, ora informadas por uma visão muito parcial das transformações necessárias à participação das pessoas deficientes na vida social, onde o acesso ao trabalho remunerado assume um papel central. Em todo o caso incapazes de desafiar a ideia de "tragédia pessoal" à luz da qual a experiências das pessoas com deficiência é hegemonicamente aprendida.

Defendo que esse fracasso resulta do facto de a experiência e a reflexividade das pessoas com deficiência nunca ter sido posta no primeiro plano. Isto, quer na definição das medidas e políticas capazes de garantir a igualdade de oportunidades, quer na efetiva assunção de como as suas capacidades e aspirações se debatem com barreiras e discriminações mais amplas.

A maturação da providência estatal, as medidas legislativas, a informação pública e a ação da sociedade civil são fatores que podem 


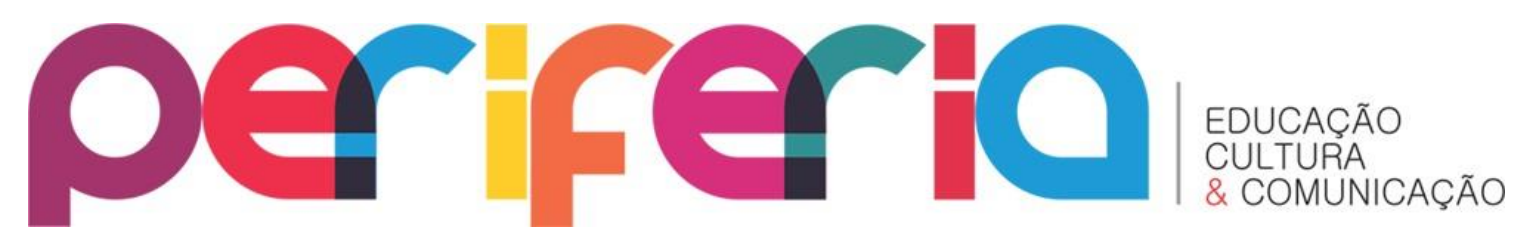

determinar parcialmente as oportunidades de inclusão social para as pessoas com deficiência nos diferentes contextos. A questão forte que deveremos perseguir é esta: será que as políticas sociais se vêm desenvolvendo no seio de uma abordagem dominante da deficiência, uma abordagem que há muito vem informando a perpetuação da desigualdade social?

É exatamente essa convicção que aqui quero avançar ao encontro das reflexões que surgiram dos movimentos de pessoas com deficiência a partir dos anos 60. Entendo que a assunção dos limites das políticas sociais é largamente produto do modo como a modernidade objectificou a experiência das pessoas com deficiência naquilo que podemos perceber como uma "reinvenção da exclusão social". Até ao fim da Idade Média as diferentes configurações dos corpos e da mente não deixam de ser associadas a valores excludentes, quase sempre de ordem metafísica. No entanto persistiu a ausência de uma noção de norma e uma visão relativista do corpo que havia de durar até ao século XVIII (MIRZOEFF, 1995). Foi então que, sob a égide do idioma da biomedicina, um conjunto de condições foi reunida sob o conceito de deficiência, estabelecendo-se um inédito "parentesco" entre pessoas que até então só tinham em comum o costume da pobreza. Apesar do paradigma biomédico ter "libertado" as pessoas em que identificou uma deficiência de uma pletora de interpretações, superstições e crenças, abrindo caminho a importantes promessas para as suas vidas, ele não deixou de impor novos fechamentos de sentido. Em particular, deveremos confrontar as consequências do conceito de deficiência ter emergido como uma formação patológica por oposição ao modelo de normalidade corporal que rege as práticas e os discursos da medicina. Assim, a noção de deficiência, marcadamente moderna, é, grosso modo, uma interligação entre o caráter duradouro ou permanente de uma anormalidade física, a visibilidade dessa anormalidade, e a incapacidade funcional que ela implica.

Primeiramente, haverá a considerar que "o efeito da medicalização dos problemas sociais é a sua despolitização" (BARNES et al., 1999, p. 60). 0 facto de a deficiência ter sido medicamente definida como algo respeitante 


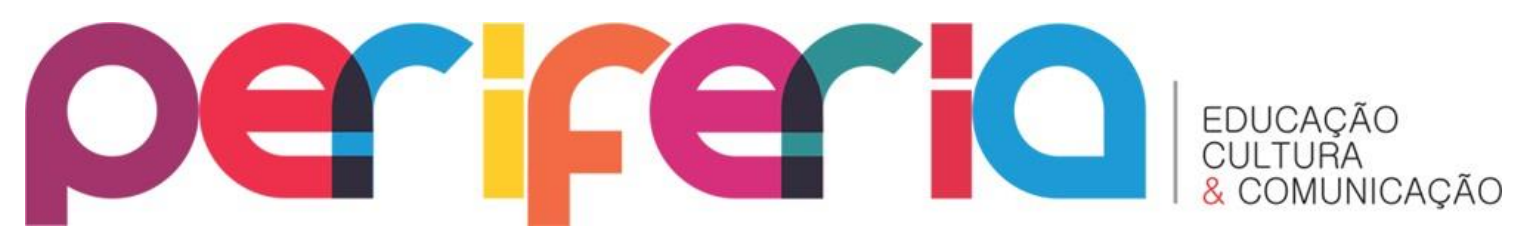

ao corpo individual foi um fator decisivo para que sempre tivessem sido privilegiadas respostas centradas no indivíduo, pouco dispostas a perceber as questões sociais envolvidas. Ademais, as respostas aí informadas sempre se basearam na ideia de que as decisões envolvidas acerca da deficiência deveriam estar sempre a cargo dos profissionais, as vanguardas do saber. Tal relação de autoridade fundou uma desqualificação das perspectivas das pessoas com deficiência, perspectivas onde os limites e desigualdades impostos pela ordem social tendem a ocupar lugar central.

Em segundo lugar, os "movimentos normalizantes" próprios da medicina vieram a estruturar os movimentos dominantes que definem os itinerários da integração social. As práticas curativas da medicina baseiam-se na supressão da anormalidade e na restituição do corpo a um desejável estado de normalidade. A questão é que, embora o exercício da medicina, enquanto prática curativa, pouco intervenha nos corpos descritos como deficientes, são os seus modelos e discursos que, até hoje, informam as respostas sociais dominantes à deficiência. Há, pois, que denunciar o pernicioso lugar ocupado por uma normalização que, ao invés de reconhecer as diferenças implicadas pelas deficiências, frequentemente impõe necessidades em vez de as reconhecer. Estamos perante uma lógica dominante que funda um investimento de saberes sobre as deficiências que, na impossibilidade da cura, propõe a reabilitação e, na impossibilidade da adesão à norma, propõe a possível supressão do desvio. Como essa supressão do desvio não equivale à efetiva restituição à normalidade, neste quadro a deficiência está fadada a não ser entendida como diferença, mas sim como fatal subalternidade.

Esta "abordagem reabilitacional", marcadamente medicalizada, individualizada e normalizante estabeleceu-se na modernidade como a abordagem dominante. E é no seio dessa abordagem que as políticas sociais relativas à deficiência se têm instalado. Assim, podemos identificar a vigência hegemónica de uma lógica cujo enfoque limitado limita também os objetivos que propala. 0 modo como cada sociedade se propõe confrontar os constrangimentos que a modernidade ocidental herdou e embutiu na 


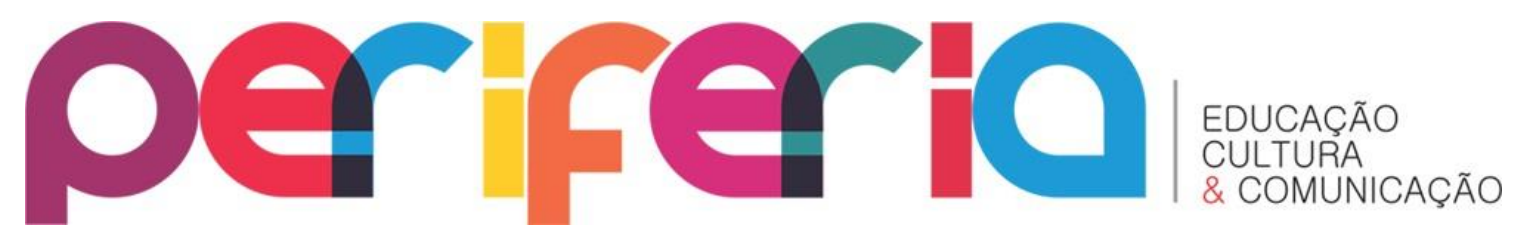

experiência da deficiência é, pois, decisivo para analisar as possibilidades para uma transformação social inclusiva.

Apesar de sucessivas propostas legislativas e do continuado desenho de políticas sociais, elaboradas no propalado desígnio de conduzir a uma inclusão social das pessoas com deficiência, a realidade social em Portugal segue dando prova de uma tenaz perpetuação deste quadro excludente (MARTINS, 2006; FONTES, 2009; MARTINS; FONTES, 2016 ).

\section{EDUCAÇÃO}

Ao nível do ensino, seguindo as tendências vindas de outros países europeus, a educação especial $e$ as suas instituições viriam a ser progressivamente desmobilizadas em favor do ensino integrado no sistema educativo regular público. Esta passagem começou a ser paulatinamente introduzida em Portugal desde os anos 60 e ficou estabelecida com a definição, na Constituição da República, publicada em 1976, de políticas de integração das pessoas deficientes na sociedade. E, em termos internacionais, daria um passo mais com a consagração do conceito de escola inclusiva, promovido na conferência de Salamanca, organizada pela UNESCO em 1994, sob o tema das necessidades educativas especiais.

Mas, como várias organizações de deficiência em Portugal defendem, na verdade, operou-se uma destruição de estruturas de ensino especial, para se dar lugar a um ensino integrado em que a escolaridade e aprendizagem das pessoas com deficiência é marcada por uma profunda precariedade. Embora seja consensualmente aceite o princípio de que o ensino em instituições regulares confere às pessoas deficientes o benefício de estudar num ambiente regular, preparando-as desde logo para uma vida em sociedade (a que se junta também o papel pedagógico para a sociedade advindo da intimidade com a diferença da deficiência), o que se verifica é que este princípio não tem sido feito valer com meios que permitam uma educação apropriada às 


\section{periferio}

crianças, jovens e restantes pessoas com deficiência. Verifica-se que o legislado no Decreto-Lei 319/91, onde se contemplam os imperativos em relação aos "alunos com necessidades educativas especiais" e a desejável construção de uma "escola para todos", sempre esteve longe de ser alcançado na prática. Isso bem o representa este excerto constante do Livro Branco dos Direitos Humanos das Pessoas com Deficiência (Associação Portuguesa de Deficientes [APD], 2002): "Contactei a senhora diretora da escola e fiquei a saber que a escola não tinha muitos meninos com problemas e que a escola inclusiva não tem condições, nem meios para ser uma escola inclusiva e o Ministério, quando decidiu isso, não sabia o que estava a fazer".

Para além dos edifícios serem frequentemente inacessíveis, são muitas as situações em que o acesso ao material em formato disponível se dá tardiamente, e em que os professores de apoio, já de si escassos, revelam uma assombrosa falta de formação específica. Como resultado, verificam-se não apenas taxas de abandono escolar que tendem a ser elevadas entre as pessoas com deficiência, mas também carências de aprendizagem, de saberes específicos necessários de formas alternativas de realização, sendo que, por vezes, devido a algum facilitismo, as competências adquiridas nem sequer correspondem aos níveis de escolaridade obtidos pelos alunos. Como refere Fernando Jorge (professor de apoio educativo ligado à deficiência visual), num texto apresentado no grupo consultivo da Direção Nacional da Associação de Cegos e Amblíopes de Portugal (ACAPO): “É claro que, perante tantas contradições e tantas dificuldades ao nível da formação de recursos humanos e no apetrechamento das escolas com meios materiais, por vezes é natural que se caia no desânimo. (...) manuais que chegam muitos meses depois de serem precisos, transcrições para Braille feitas com a conhecida máquina Perkins, pouco cuidado com o ensino das Técnicas de Orientação e Mobilidade e com a utilização dos meios informáticos. (...) O que tem acontecido com os alunos deficientes visuais, e em especial com aqueles que usam o Braille, é estarem na completa dependência do Sistema, o qual é claramente ineficaz, 


\section{periferio}

tanto ao nível da produção de material adaptado como no âmbito do apoio por pessoal qualificado".

Este é, sem dúvida, um grave problema, que naturalmente afeta as possibilidades das pessoas com deficiência, na aquisição de competências pessoais, culturais, e, em particular, nas suas perspectivas no mercado de trabalho, estando gravemente lesado o princípio da igualdade de oportunidades no que às possibilidades de habilitação educativa diz respeito. Isto mesmo me dizia Humberto Santos, presidente da Associação Portuguesa de Deficientes: "O que é que significa hoje uma criança chegar à escola e não ter igualdade de oportunidades de aprendizagem? É que uma criança não aprendendo hoje, o que vai acontecer é que não vai ter entrada no mercado de emprego quando for adulta! Nós não investimos tostões para depois perdermos milhões, ou seja, há aqui perdas em catadupa...".

Por seu lado, a situação que se vive no ensino superior está, também ela, longe de oferecer uma visão otimista acerca do lugar que a educação poderia, e deveria, ocupar no alicerçar das possibilidades de inserção social das pessoas com deficiência. Em primeiro lugar, haverá a considerar o modo como tem sido inviabilizado o acesso de pessoas com deficiência a diversos cursos superiores, com base em pré-requisitos. A questão é que estes requisitos se fundam frequentemente em preconceitos discriminatórios, ou mais não são do que a assunção da ausência de estruturas e recursos para que o acesso dos estudantes com deficiência ao ensino superior possa ser feito em igualdade de oportunidades com os demais. Depois, para cúmulo, se até ao secundário nos deparamos com situações em que a responsabilidade do Estado na inclusão das pessoas com deficiência não obedece aos princípios legislados, na universidade existe um vazio legal, dependendo da vontade de cada instituição a criação de organismos próprios. 0 vazio legislativo existente faz com que apenas 4 universidades em Portugal tenham desenvolvido, por sua iniciativa, estruturas de apoio às pessoas com deficiência, estruturas que não obedecem a uma qualquer lógica comum. E, consoante me referia a responsável por um desses centros, na Universidade de Coimbra, mesmo na 


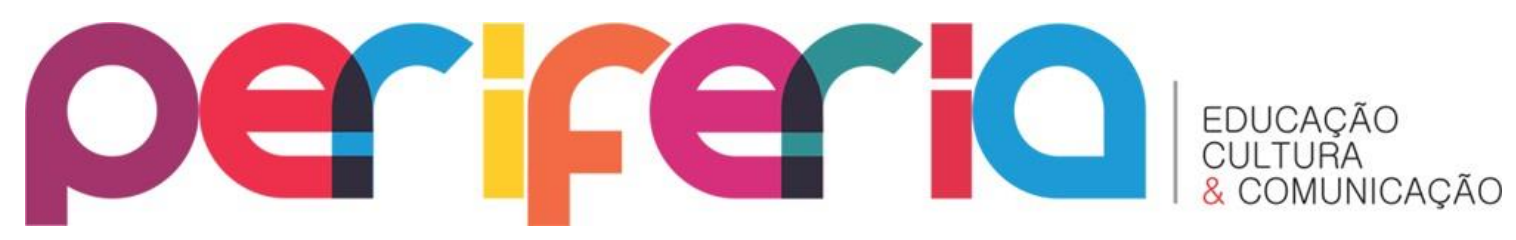

dita universidade em que uma tal estrutura existe, estão longe de serem criadas, em termos de recursos físicos, humanos e materiais, condições para que as pessoas com deficiência possam estudar autonomamente e em igualdade de oportunidades com os demais. Este é um dado que se mostra por demais expressivo em relação à situação que encontraremos na esmagadora maioria de instituições universitárias, onde não existe qualquer tipo de estrutura de suporte.

Portanto, a educação emerge, logo à partida, como um fator que promove a discriminação das pessoas com deficiências, cerceando o seu acesso ao conhecimento e à obtenção de um património que permita a inserção no mercado de trabalho. A situação de desemprego e trabalho precário, que afeta uma grande percentagem das pessoas com deficiência, resulta, por isso, em grande medida, das vulnerabilidades do sistema educativo.

\section{DEMOCRACIA E PARTICIPAÇÃO}

Quando analisamos as políticas estatais, não poderemos esquecer que a apreciação das dinâmicas específicas que definem as medidas que se dirigem às pessoas com deficiência nos colocam, inevitavelmente, perante um outro fator constitutivo da política social: o facto de ela ser produto da luta política. Nesse sentido, sendo verdade que o quadro no qual a deficiência foi modernamente “inventada" apresenta uma poderosa vocação para a naturalização da subalternidade, os diferentes contextos sociais não deixam de apresentar matizes que muito se ligam ao papel a ser desempenhado pela intervenção politica e pela participação democrática.

$\mathrm{Na}$ medida em que as pessoas que melhor conhecem as implicações dos desenhos sociais na vida das pessoas com deficiência são as próprias, e na medida em que a sua agenda ocupa um lugar marginal nas formas representativas de democracia, torna-se fácil perceber importância de uma ação sociopolítica a ser engendrada por via da democracia participativa. Tal 


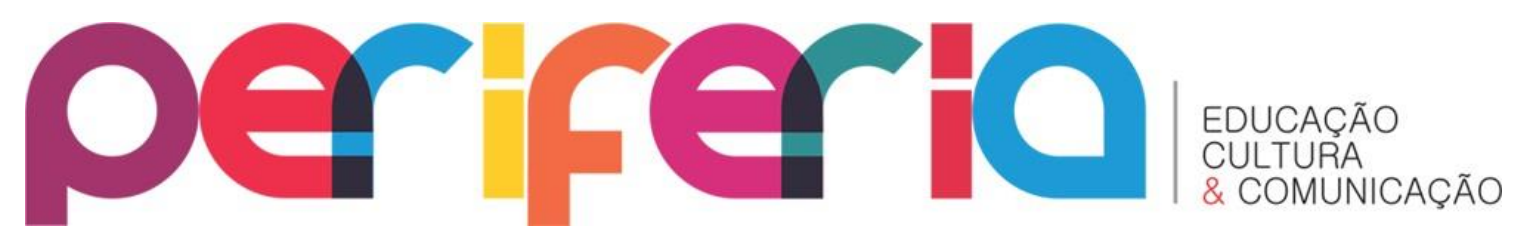

dinâmica deveria ser capaz de articular a manifesta diferença implicada pela deficiência - o mesmo é aludir aos estigmas que a apreendem socialmente com uma efetiva equalização de oportunidades. Isto mesmo é veiculado pelas "Regras Gerais" da ONU: "Os Estados devem promover e apoiar financeiramente e de outras formas a criação e consolidação de organizações de pessoas com deficiência, de associações de famílias e/ou de pessoas que defendam os seus direitos. Os Estados devem reconhecer o papel daquelas organizações no desenvolvimento das políticas em matéria de deficiência".

Perante isso, os horizontes para a transformação da situação das pessoas com deficiência em Portugal remetem-nos largamente para aqueles que são alguns dos traços marcantes da sociedade civil portuguesa e da sua relação com o Estado. Assim, de um modo breve, e seguindo a leitura com que Boaventura Sousa Santos $(1993 ; 1994 ; 1990)$ vem apreendendo algumas das singularidades da realidade portuguesa, podemos dizer que Portugal se caracteriza por um "défice de movimento social" (SANTOS, 1990, p.230), défice que assoma de um modo mais óbvio quando comparamos Portugal com a realidade dos países centrais europeus. Entre as muitas razões que poderíamos convocar, a compreensão deste facto muito deve ao facto de Portugal ter estado longamente sujeito a um regime político autoritário - o mais longo da Europa ocidental no século XX. Isto afere-se de várias maneiras nas formas organizadas de ação das pessoas com deficiência: 1 - uma recente cultura de direitos e uma democracia participativa frágil - expressa na reduzida mobilização politica das pessoas com deficiência; 2- um Estado que permanece com alguns traços de centralismo autoritário - algo que se expressa na sua relação com as organizações de pessoas com deficiência: na negação da participação na tomada de decisões acerca das políticas sociais, e numa lógica de financiamento que visa controlar a vida das organizações; 3 um Estado Providência fraco que faz com que as organizações procurem compensar os seus défices na prestação de serviços sociais, dado que se reflete no facto de as organizações acabarem por dirigir muitos dos seus esforços e recursos para providenciar serviços que o Estado não assegura. 


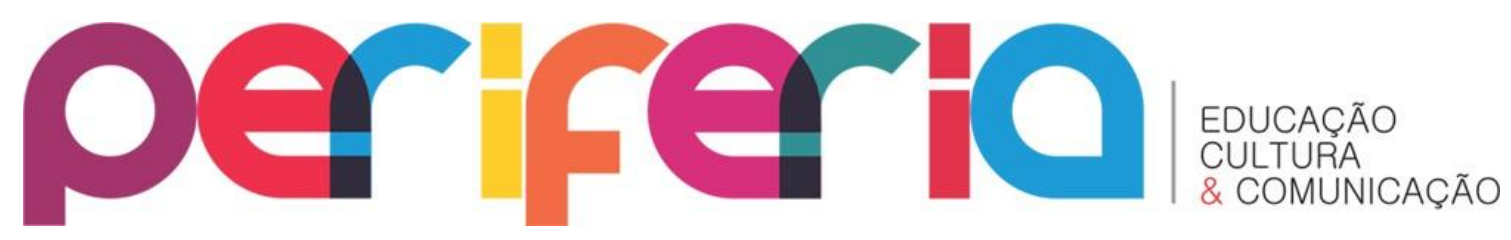

A ditadura que entre 1928 e 1974 se estabeleceu em Portugal teve um grande impacto em todas as esferas da sociedade portuguesa, incluindo nas vidas de pessoas com deficiência. O controlo sobre a sociedade civil impediu qualquer atividade política e o desenvolvimento de movimentos sociais até 1974. Apesar da existência de organizações de pessoas com deficiência desde os anos 1920 e 1930, nenhuma delas estava politicamente envolvida na questão da deficiência (FONTES, 2011). Em vez disso, dedicavam-se a ações de caridade, atuavam fora dos espaços públicos, nomeadamente em grupos de desporto ou espaços de encontro para pessoas cegas ou surdas. O cenário começou a mudar com a criação da Associação Portuguesa de Deficientes, em 1972, e da Associação dos Deficientes das Forças Armadas, ${ }^{2}$ em 1974. Até então a ditadura teve um impacto direto nas relações entre a sociedade civil e as estruturas do Estado. De facto, as reminiscências do tempo ditatorial estão bem refletidas no modo autoritário como o Estado se relaciona com as organizações de pessoas com deficiência.

A fragilização da participação política das pessoas com deficiência deve tanto à parca democratização das relações entre Estado e as organizações representativas, em virtude de uma inércia sociopolítica marcada pelo autoritarismo, como à vulnerabilidade económica que pouco liberta as organizações e as pessoas com deficiência para uma ação política mais consequente. Também neste aspeto particular se faz sentir a herança da ditadura. A supressão da ideia de Estado Social - com a assunção por parte do Estado de um papel secundário na provisão de proteção social - e a afirmação de uma lógica assistencialista, na qual a deficiência se erigia mormente como uma questão da caridade, estabeleceu uma lógica paternalista que ainda hoje se sobrepõe ao reconhecimento da autonomia política e económica enquanto direito que enriquece o espaço democrático. Portanto, a realidade portuguesa parece dar conta do reduzido empenho do Estado e da falta de capacidade da sociedade civil para transformar as condições de desigualdade social a que as

\footnotetext{
2 Resultado direto da mobilização dos ex-combatentes que adquiriram deficiência na Guerra Colonial portuguesa (1961-1974).
} 


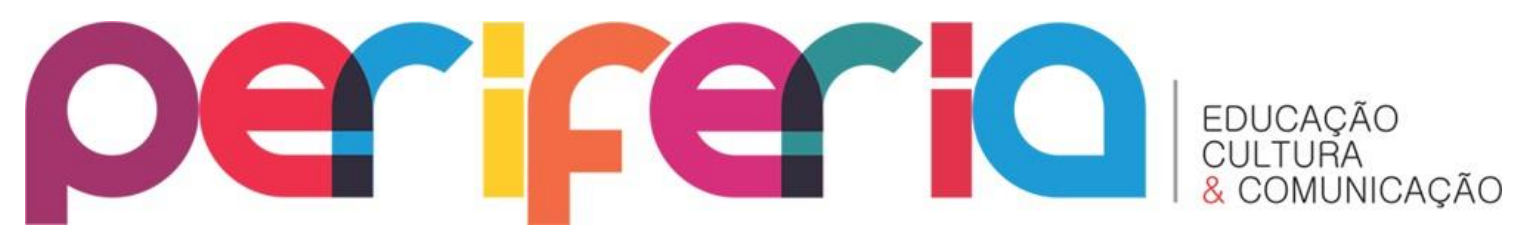

pessoas com deficiência estão sujeitas, isto no mesmo momento em exprime o quão urgente essa transformação seria necessária. Essa fragilidade verte-se na inconsequência das transformações legislativas.

\section{DA LEI À INCLUSÃO}

Neste quadro, em que os valores culturais e as práticas sociais ainda alimentam uma noção individual assistencialista, caritativa e reabilitacional da deficiência, e onde a vitalidade da democracia está fortemente coartada, como receber as propostas legislativas que se dirigem à criação de igualdade de oportunidades? Com inevitável prudência, evitando triunfalismos sem sentido, e com uma forte consciência que muitas vezes as leis, desarticuladas de outras dinâmicas, mudam para que tudo fique na mesma. É em si positivo que as leis caminhem à frente dos valores na medida em que, além do óbvio papel de punir e vigiar incumprimentos, elas podem cumprir um papel de pedagogia social, arrastar outras dinâmicas e novos discursos. A questão que convém reter, cautelarmente, é que, conforme refere Boaventura Sousa Santos, "quanto mais caracterizadamente uma lei defende os interesses populares e emergentes maior é a probabilidade de que ela não seja aplicada" (1994, p. 155).

A questão essencial é que no caso português as transformações legislativas relativas à deficiência não têm sido acompanhadas por uma dinâmica de transformação das perceções sociais acerca da deficiência, algo que frequentemente leva ao esvaziamento dos propósitos na lei. Por outro lado, a precariedade com que vivem as organizações não thes confere cabais condições para inviabilizarem, quer ao nível judicial quer ao político, os sistemáticos incumprimentos da lei.

A fragilidade democrática associada a uma cultura dominante marcada pela "narrativa da tragédia pessoal" deve-nos concitar à compreensão dos perigos que tantas vezes minam as transformações legislativas: 1 - 0 perigo de na prática quotidiana os elementos da administração pública, os 


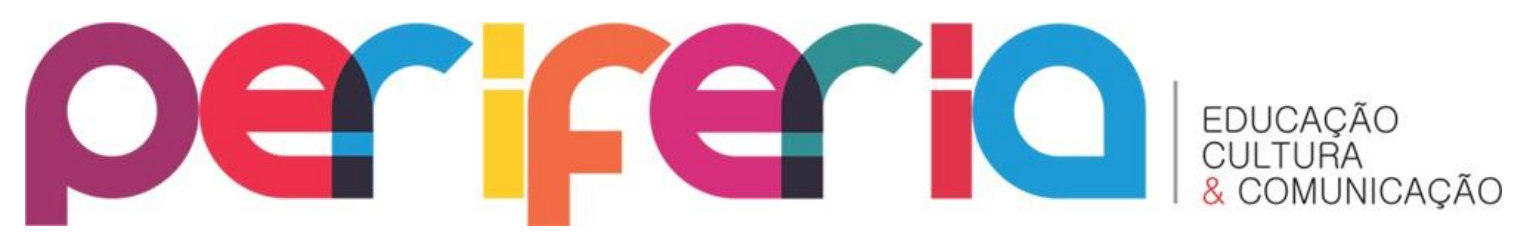

empregadores privados, os engenheiros e arquitetos, educadores, programadores culturais não estarem enculturados nos direitos das pessoas com deficiência. 2- 0 perigo de nos próprios tribunais se refletirem preconceitos e estereótipos. Os agentes judiciais não estão livres de preconceitos, se não forem culturalmente imbuídos num modelo social da deficiência, muitas vezes inscrevem nas suas decisões valores que ainda não estão familiarizados com a magnitude do desafio de uma sociedade inclusiva no que às pessoas com deficiência diz respeito. 3- 0 perigo de surgirem leis sem um sério esforço de envolvimento das organizações interessadas e da opinião pública. 4- 0 perigo de se confiar excessivamente na transformação legislativa quando esta não é acompanhada por mudanças nas representações culturais. Isto acontece porque muitas vezes se vê uma lei como o fim do caminho. Importa é que a lei que contribua para uma pedagogia social e tenha efetividade nos tribunais, até porque os casos exemplares têm frequentemente um valor pedagógico. 5 - 0 perigo de as leis transformativas serem redigidas com ambiguidades que fragilizam os seus propósitos transformativos, facilitando que seja capturada pelos valores instalados.

\section{CONCLUSÃO}

Uma análise crítica do lugar que as pessoas com deficiência ocupam nas sociedades ocidentais - ou nas sociedades em que os paradigmas modernos ocidentais se tornaram hegemónicos - identifica, hoje, duas frentes de opressão que se complementam e confundem. Estas formas de opressão, na nossa perspetiva, reclamam dois projetos de transformação que incitam leituras alternativas da epistemologia moderna, dos corpos, do Estado, dos movimentos políticos e das organizações não-governamentais.

Em primeiro lugar, assinalamos a gramática opressiva resultante da sagração moderna do conceito de normalidade que, demarcando sujeitos “normais" e "não normais", define as possibilidades de habitar a modernidade. No caso das pessoas com deficiência, a permeabilidade da 


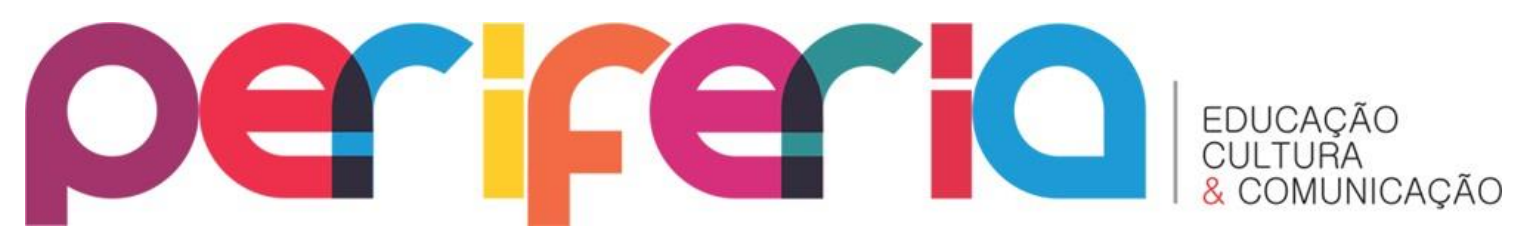

modernidade à celebração da norma traduziu-se na apropriação dos seus corpos e das suas vidas pela medicina (que, no limite, implicou a negação do próprio direito à vida, bem representado pelo fulgor das teorias eugenistas), e veio definir territórios circunscritos por férreas fronteiras de inferioridade, constituindo uma categoria de "menos humanos".

Em segundo lugar, identificamos opressão que resulta do modo como os Estados são cúmplices de um regime de desigualdade de oportunidades, reproduzindo a exclusão nas estruturas discriminatórias que vigoram na educação, no emprego, nos transportes, no acesso ao espaço público, etc. Esta estrutura que ora atua por discriminação ativa ora por negligência, ligase hoje a um momento em que o papel do Estado é colocado em causa por uma agenda neoliberal que, com diferentes tempos e diferentes latitudes, preconiza o desinvestimento público e dá cobertura a um economicismo com profundos custos sociais e, no limite, com repercussões económicas negativas. Em causa está um ambiente económico que promove o esvaziamento do papel do Estado enquanto horizonte de inclusão, logo concertando, quanto muito, lógicas "paliativas" que mais não fazem do que assegurar o limiar de sobrevivência das pessoas com deficiência. Trata-se de um arranjo económico que no longo prazo é bem mais oneroso do que aquele que resultaria da efetiva participação social, política e económica desta minoria significativa. A reprodução das lógicas que cerceiam a participação constitui as pessoas com deficiência enquanto "menos cidadãos".

Precisamos por isso de perceber os limites de uma abordagem reabilitacional e caminhar para um modelo mais social da deficiência, ou seja, importa que as respostas sociais à deficiência possam considerar que vivemos num regime profundamente opressivo no que às pessoas com deficiência diz respeito. Há, portanto, um caminho de transformação social mais ampla tem que nutrir e ser nutrido por uma desestabilização das representações dominantes da deficiência e por uma vitalidade democrática. Só essa vitalidade, que carece de uma capacitação financeira das organizações de pessoas com deficiência, permitirá que a imagem pública da deficiência tenha 


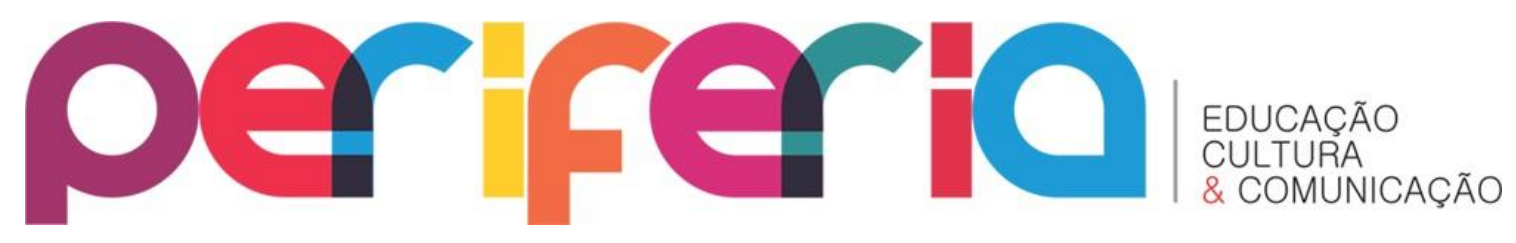

cada vez com uma lógica identitária onde se afirmem capacidades ante a reivindicação pela superação de barreiras, em vez da linguagem comisera ante a mão assistencialista.

Na perspetiva em que me situo, importa reconhecer a deficiência como parte significativa de uma modernidade subalternizada, na qual as vidas das pessoas com deficiência podem ser entendidas como itinerários insubmissos capazes de guiar as ciências sociais à sua própria insubmissão. Concebemos as experiências da deficiência como narrativas de resistência, sugerindo uma proximidade instrutiva em que a academia assume, em primeiro lugar, a capacidade de escutar como estratégia e, em segundo, a transformação da sociedade como aspiração maior à validade do seu conhecimento.

\section{REFERÊNCIAS}

APD. Livro Branco dos Direitos Humanos das Pessoas com Deficiência. Lisboa: APD, 2002

BARNES, Colin. Extended Review: Disability and Paid Employment. Work, Employment and Society, v. 13, n. 1, p. 147-149, 1999.

BARNES, Colin; MERCER, Geof; SHAKESPEARE, Tom. Exploring disability: a sociological introduction. Cambridge: Polity Press, 1999.

DAVIS, Lennard. Enforcing Normalcy: Disability, Deafness and the Body, Londres, Verso.

FONTES, Fernando. Pessoas com deficiência e políticas sociais em Portugal: da caridade à cidadania social. Revista Crítica de Ciências Sociais, n. 86, p. 7393, 2009.

FONTES, Fernando. Social Citizenship and Collective Action: The Case of the Portuguese Disabled People's Movement. Tese de doutoramento. Leeds: University of Leeds, 2011.

GONÇALVES, Cristina. Enquadramento familiar das pessoas com deficiência: uma análise exploratória", Revista de Estudos Demográficos, n. 33, INE, Lisboa, 2003.

MARTINS, Bruno Sena (2006), E se eu Fosse Cego: Narrativas Silenciadas da Deficiência. Porto: Afrontamento, 2006. 


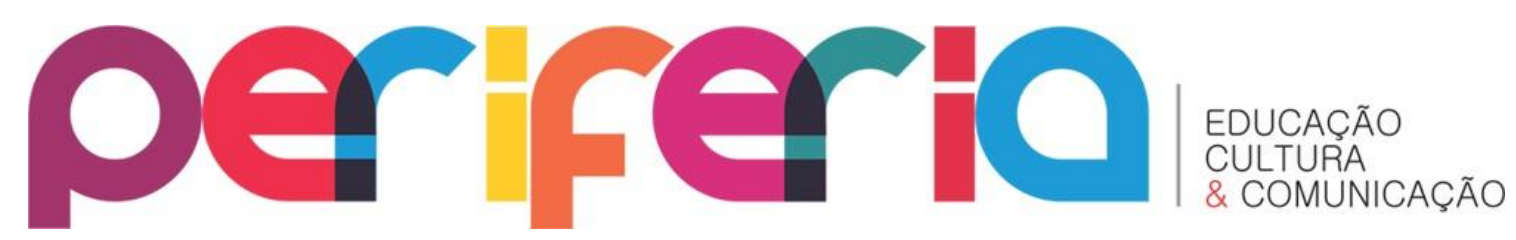

MARTNS, Bruno Sena; FONTES, Fernando (orgs.) (2016), Deficiência e emancipação social - Para uma crise da normalidade. Coimbra: Almedina, 2016.

MIRZOEFF, Nicholas. Bodyscape: Art, Modernity and the Ideal Figure. Londres: Routledge, 1995.

MISHRA, Ramesh. O Estado Providência na Sociedade Capitalista. Oeiras: Celta, 1990.

OLIVER, Michael. The Politics of Disablement. The Macmillan Press Ltd: Houndmills, 1990.

SANTOS, Boaventura de Sousa. 0 estado, as relações salariais e o bem-estar social na semiperiferia: o caso português. In: SANTOS, Boaventura de Sousa (org.). Portugal: Um Retrato Singular. Porto: Afrontamento, 1993.

SANTOS, Boaventura de Sousa. O Estado e a Sociedade em Portugal (19741988). Porto: Afrontamento, 1990.

SANTOS, Boaventura de Sousa. Pela Mão De Alice: O Social e o Político Na PósModernidade. Porto: Afrontamento, 1994.

SNR. Normas Sobre Igualdade de Oportunidades para Pessoas com deficiência. Lisboa: Secretariado Nacional para a Reabilitação e Integração das Pessoas com Deficiência, 1995. 